\title{
ASSOCIATION BETWEEN SERUM MATRIX METALLOPROTEINASE-12/ANGIOTENSIN II PROFILE AND LEFT VENTRICULAR HYPERTROPHY IN PATIENTS WITH HEART FAILURE
}

\author{
Asparuh G. NIKOLOV ${ }^{1 凶}$, Maria L. TZEKOVA², Konstantin M. KOSTOV², \\ Alexander B. BLAZHEV ${ }^{3}$ \\ ${ }^{1}$ Institute for Scientific Research, Cardiovascular Research Working Group, Medical University, Pleven, \\ Bulgaria \\ ${ }^{2}$ Department of Propaedeutic of Internal Diseases, Second Clinic of Cardiology, Medical University, Pleven, \\ Bulgaria \\ ${ }^{3}$ Division of Biology, Medical University, Pleven, Bulgaria
}

Received 15 Mar 2020, Corrections received 03 Apr 2020, Accepted 04 May 2020

https://doi.org/10.31688/ABMU.2020.55.2.04

\section{Abstract}

Introduction. Matrix metalloproteinases (MMPs) are important target genes for angiotensin II (AII), which subsequently alters MMP expression in extracellular matrix (ECM) and lead to remodeling process.

Objective. To investigate whether an association between serum levels of MMP-12, AII and left ventricular hypertrophy exists in patients with heart failure with mid-range ejection fraction (HFmrEF) and arterial hypertension (AH)

Material and methods. 56 patients with $\mathrm{HFmrEF}$ and $\mathrm{AH}$ were examined, mean age $65.62 \pm 9.69$ years, and 22 age and sex-matched healthy subjects, mean age $56.4 \pm 5.53$ years. 41 patients had hypertension-mediated organ damage and 15 did not. Patients were divided in two subgroups: subjects with left ventricular hypertrophy $(\mathrm{n}=32),(\mathrm{HFmrEF}+\mathrm{LVH})$, and subjects without left ventricular hypertrophy $(n=24)$, (HFmrEF-LVH). ELISA was used for measuring AII and MMP-12.

\section{RÉSUMÉ}

Association entre le profil de la métalloprotéinase matricielle dans le sérum-12/angiotensine II et l'hypertrophie ventriculaire gauche chez des patients atteints d'une insuffisance cardiaque

Introduction. Les métalloprotéinases matricielles (MMP) sont des gènes cibles importants pour l'angiotensine II (AII), qui modifient par la suite l'expression des MMP dans la matrice extracellulaire (ECM) et conduisent à un processus de remodelage.

L'objectif de l'étude a été de déterminer s'il existe une association entre les taux sériques de MMP-12, AII et l'hypertrophie ventriculaire gauche chez les patients atteints d'insuffisance cardiaque avec une fraction d'éjection moyenne (HFmrEF) et d'hypertension artérielle (AH).

Matériel et méthodes. 56 patients avec HFmrEF et AH ont été examinés, âge moyen $65.62 \pm 9.69$, et 22 
Results. Serum MMP-12 levels were statistically significant lower in patients, than in controls: 0.0033 $\mathrm{ng} / \mathrm{mL}(0.0022 \div 0.0071)$ vs. $0.0075 \mathrm{ng} / \mathrm{mL}(0.0068$ $\div 0.016)(\mathrm{KW}=7.37$; $\mathrm{p}=0.006)$. MMP-12 showed correlation with grade of $\mathrm{AH}(\mathrm{r}=0.28 ; \mathrm{p}=0.03)$. Patients with $\mathrm{HFmrEF}+\mathrm{LVH}$ showed statistically significant higher levels of AII: $8.533 \mathrm{pg} / \mathrm{mL}(1.477 \div 13.009)$ than HFmrEF-LVH $1.333 \mathrm{pg} / \mathrm{mL}(0.477 \div 6.932)$ and healthy controls $1.539 \mathrm{pg} / \mathrm{mL}(0.274 \div 5.218) ;(\mathrm{KW}=3.48$; $\mathrm{p}=0.04)$. AII correlated with stage of $\mathrm{AH}(\mathrm{r}=0.47$; $\mathrm{p}=0.001$ ). MMP-12/AII ratio was significantly higher in patients with HFmrEF+LVH than in HFmrEF-LVH 3.867 vs. 0.0025 ( $\mathrm{p}<0.001$ ).

Conclusions. Our data suggest an association between serum MMP-12 levels, AII and grade and stage of AH. Determination of serum MMP-12/Angiotensin II profile may be a useful method for monitoring of development and progression of left ventricular hypertrophy.

Keywords: arterial hypertension, heart failure, left ventricular hypertrophy, extracellular matrix.

\section{Abbreviations list:}

ECM- extracellular matrix

CHF- chronic heart failure

MMP- matrix metalloproteinase

MME- macrophage metalloelastase

ME- macrophage elastase

AII- angiotensin II

TIMP- tissue inhibitor of matrix metalloproteinase

$\mathrm{AH}$-arterial hypertension

HfmrEF- heart failure with mid-range ejection fraction

LVEF- left ventricular ejection fraction

ESC- European Society of Cardiology

HMOD- hypertension-mediated organ damage

$\mathrm{HFmrEF}+\mathrm{LVH}$ - subjects with mid-range ejection fraction and left ventricular hypertrophy

HFmrEF-LVH- subjects with mid-range ejection fraction without left ventricular hypertrophy

CVD- cardiovascular disease

ECG- electrocardiography

$\mathrm{LVH}$ - left ventricular hypertrophy

HDL- high density lipoprotein cholesterol

LDL- low density lipoprotein cholesterol

CKD- chronic kidney disease

GFR-glomerular filtration rate

ELISA- enzyme-linked immunosorbent assay

SNP- single nucleotide polymorphisms

HETE- hydroxyeicosatetraeonic acid

CYP450- cytochrome P450

ACE- angiotensin-converting enzyme inhibitors

ARB- angiotensin II receptor blockers

BMI- body mass index

SBP- systolic blood pressure

DBP-diastolic blood pressure

CK-MB - creatine kinase myocardial band

SMCs- smooth muscle cells sujets sains appariés selon l'âge et le sexe, âge moyen 56.4 \pm 5.53 .41 des patients étaient atteints de lésions organiques médiées par l'hypertension et 15 étaient sans. Les patients étaient divisés en deux sous-groupes: sujets avec hypertrophie ventriculaire gauche $(n=32)$, $(\mathrm{HFmrEF}+\mathrm{LVH})$, et sujets sans hypertrophie ventriculaire gauche $(n=24),(H F m r E F-L V H)$. ELISA a été utilisée pour mesurer AII et MMP-12.

Résultats. Les taux sériques de MMP-12 étaient statistiquement significativement plus faibles chez les patients que chez les témoins: $0.0033 \mathrm{ng} / \mathrm{ml}(0.0022 \div$ $0.0071)$ contre $0.0075 \mathrm{ng} / \mathrm{ml}(0.0068 \div 0.016)(\mathrm{KW}=$ 7.37; $\mathrm{p}=0.006$ ). MMP-12 a montré une corrélation avec le grade d'AH $(r=0.28 ; p=0.03)$. Les patients avec $\mathrm{HFmrEF}+\mathrm{LVH}$ ont montré des niveaux statistiquement significativement plus élevés d'AII: $8.533 \mathrm{pg} /$ $\mathrm{ml}(1.477 \div 13.009)$ que HFmrEF-LVH $1.333 \mathrm{pg} / \mathrm{ml}$ $(0.477 \div 6.932)$ et des témoins sains $1.539 \mathrm{pg} / \mathrm{ml}(0.274$ $\div 5.218) ;(K W=3.48 ; \mathrm{p}=0.04)$. L’AII était corrélé avec le stade de l'AH ( $r=0.47 ; \mathrm{p}=0.001)$. Le rapport MMP-12/ AII était significativement plus élevé chez les patients avec HFmrEF + LVH que chez HFmrEF-LVH 3.867 contre 0.0025 ( $p<0,001)$.

Conclusions. Nos données suggèrent une association entre les niveaux sériques de MMP-12, l'AII et le grade et le stade d'AH. La détermination du profil sérique MMP-12/angiotensine II peut être une méthode utile pour surveiller le développement et la progression de l'hypertrophie ventriculaire gauche.

Mots-clés: hypertension artérielle, arrêt cardiaque, hypertrophie ventriculaire gauche, matrice extracellulaire. 


\section{INTRODUCTION}

Collagen fibrils, elastin fibers and fibroblasts are major structural components of extracellular matrix $(\mathrm{ECM})^{1}$. Macrophages, macromolecules, such as glycoproteins, glycosaminoglycans, together with other molecules such as growth factors, cytokines and extracellular proteases take part in this structure's props too. Myocardial collagen matrix may be conceptualized as scaffolding providing structural integrity ${ }^{2}$. Traditionally, cardiac ECM is considered a relatively inactive structure, playing an important framework role for cardiac myocytes and vessels. Recent data provide evidence that cardiac ECM is a dynamic and metabolically active structure. Cardiac extracellular matrix changes are suspected of contributing to the genesis and progression of heart failure ${ }^{3}$.

Elastin is a connective tissue protein characterized by highly elasticity. It is a major ECM component and allows many tissues in the body to resume their shape after stretching or contracting ${ }^{4}$. Elastin is involved in cardiac ECM structure and function ${ }^{5}$. Elastin turnover is regularized mainly by MMP-12 and TIMP-3. Currently, there are insufficient data of elastin turnover in chronic heart failure (CHF). Investigation of elastin turnover should help to better understanding the role of ECM in the pathogenesis of $\mathrm{CHF}$. Abnormal changes in cardiomyocytes structure might not be the only pathophysiological mechanism involved in development and progression of heart failure. That is why the focus of our study is myocardial ECM. This might help for a better understanding of CHF pathogenesis and possible future therapies.

Matrix metalloproteinase-12 (MMP-12), also known as macrophage metalloelastase (MME) or macrophage elastase (ME), is an enzyme encoded by the MMP12 gene. The major MMP-12 substrate is elastin. Moreover, MMP-12 is capable of degrading other ECM constituents (but not gelatin) and many nonmatrix proteins in vitro. Most MMP's are secreted as inactive proproteins. The enzyme degrades soluble and insoluble elastin ${ }^{6}$. MMP12 plays a role in aneurysm formation and Stanford-A acute aortic dissection and studies in mice and humans suggest a role in the development of emphysema. MMP-12 is also involved in tissue remodeling in Fas-Induced lung fibrosis, and in fibrotic diseases, including systemic sclerosis (SSc), and correlates with vasculopathy and fibrosis, potentiating skin and heart fibrosis in these patients?

There is evidence that plasma level of MMP-7 and -12 are elevated in type 2 diabetes mellitus, associated with more severe atherosclerosis and an increased incidence of coronary events. These observations provide clinical support to previous experimental studies, demonstrating MMPs' role in plaque development. Data suggest that MMP-7 and-12 are potential biomarkers of atherosclerosis' burden and cardiovascular disease risk ${ }^{8}$.

A study showed that „early matrix metalloproteinase-12 inhibition worsens post-myocardial infarction cardiac dysfunction by delaying inflammation resolution in mice. Their results reveal a novel protective mechanism for MMP-12 in neutrophil biology. Post-myocardial infarction, MMP-12 impaired CD44HA interactions to suppress neutrophil apoptosis and prolong inflammation, which worsened left ventricular function"

Angiotensin II (AII) is the main component of the renin-angiotensin system. AII is associated with cardiovascular diseases such as hypertension, vascular remodeling and inflammation. Dysregulation of matrix metalloproteinases (MMPs) and their tissue inhibitors (TIMPs) results in a remodeling process. Moreover, MMPs are considered as important target genes for angiotensin II.

There is growing evidence which supports the opinion that AII may directly cause cardiovascular and renal diseases, independent of its hypertensive effect. Recent scientific data have provided new insights into the molecular and cellular mechanisms of AII-mediated cardiovascular and renal diseases. AII exerts direct effects on vascular remodeling and function $^{10}$. Arterial hypertension (AH) is a leading cause for a large number of heart failure (HF) cases. Heart failure with mid-range ejection fraction $(\mathrm{HFmrEF})$ is a syndrome defined by: (1) left ventricular ejection fraction (LVEF) 40-49\%; (2) symptoms and/or signs of heart failure; (3a) elevated levels of natriuretic peptides; (3b) at least one additional criterion: relevant structural heart disease (left ventricular hypertrophy/ left atrial enlargement) or diastolic dysfunction, according to the 2016 European Society of Cardiology (ESC) Guidelines for the diagnosis and treatment of acute and chronic heart failure ${ }^{11}$.

In 2005, researchers showed that AII stimulates matrix metalloproteinase secretion in human vascular smooth muscle cells via nuclear factor-kappa B and activator protein 1 in a redox-sensitive manner. „The renin-angiotensin system contributes to atherogenesis. Matrix metalloproteinases (MMP) are thought to participate in plaque destabilization through degradation of extracellular matrix "12.

In 2010, investigators revealed that AII differentially induces matrix metalloproteinase- 9 and tissue inhibitor of metalloproteinase-1 production and disturbs MMP/TIMP balance ${ }^{13}$. The aim of the study was to determine the effects of angiotensin II on MMP-9 and TIMP-1 production and MMP/TIMP balance in a monocytic cell type. It is induced more efficiently than TIMP-1 by AII that leads to MMP/ 
TIMP imbalance. Authors' data also showed the pivotal participation of these cells in pathological cardiovascular remodeling mediated by AII ${ }^{13}$.

The objective of the StUdy was to investigate whether an association between serum levels of MMP-12, AII and left ventricular hypertrophy exists in patients with heart failure with mid-range ejection fraction (HFmrEF) and arterial hypertension (AH).

\section{Material AND MEthods}

\section{Patient population}

All patients were residing in the vicinity of the Pleven University Hospital, Pleven, Bulgaria. Subjects' serum was taken by experienced staff. All the procedures followed were in accordance with the ethical standards of the responsible committee on human experimentation (institutional or regional) and with the Helsinki Declaration of 1975, as revised in 2000. The approval of local Ethics Committee was obtained and informed consent from adult research participants was obtained, too.

The study group consisted of 56 patients with $\mathrm{AH}$ and HFmrEF, mean age $65.62 \pm 9.69$ years.
Forty-one of patients had hypertension-mediated organ damage (HMOD) and 15 did not. Patients were divided in two subgroups: subjects with mid-range ejection fraction and left ventricular hypertrophy $(n=32)$, mean age $62.5 \pm 12.58$ years, $(\mathrm{HFmrEF}+\mathrm{LVH})$; subjects with mid-range ejection fraction without left ventricular hypertrophy $(n=24)$, mean age $60.4 \pm 8.4$ years, (HFmrEF-LVH) (Table 1). These values were compared to serum MMP-12/AII profile in 22 age and sex-matched controls, with no family history of diabetes, atherosclerosis or hypertension, mean age $56.4 \pm 5.53$ years.

\section{Hypertension-mediated organ damage assess- ment}

All patients were examined for HMOD via history (for established cardiovascular or premature CVD, renal, cerebrovascular or ophthalmological damage), physical examination and pulse pressure assessment (in older people) $\geq 60 \mathrm{mmHg}$.

\section{Blood pressure}

Arterial blood pressure was measured using a standard anearoid sphygmomanometer, to the nearest $2 \mathrm{mmHg}$, in the dominant arm, after at least 10-min

Table 1. Clinical data of patients and healthy controls

\begin{tabular}{|c|c|c|c|}
\hline Clinical data & HFmrEF+LVH & HFmrEF-LVH & Controls \\
\hline Age & $62.5 \pm 12.58$ & $60.4 \pm 8.4$ & $56.4 \pm 5.53$ \\
\hline Gender $(\mathrm{M} / \mathrm{F})$ & $18 / 14$ & $14 / 10$ & $12 / 10$ \\
\hline Mean duration $\mathrm{AH}$ & $9.57 \pm 6.63$ & $7.63 \pm 5.26$ & $\mathrm{~N} / \mathrm{A}$ \\
\hline Mean duration $\mathrm{HF}$ & $5.6 \pm 2.9$ & $4.89 \pm 1.60$ & $\mathrm{~N} / \mathrm{A}$ \\
\hline $\mathrm{SBP}(\mathrm{mmHg})$ & $151.35 \pm 16.05$ & $139.11 \pm 18.42$ & $118.26 \pm 13.74$ \\
\hline $\mathrm{DBP}(\mathrm{mmHg})$ & $89.05 \pm 10.32$ & $84.41 \pm 11.73$ & $76.4 \pm 8.4$ \\
\hline BMI & $28.52 \pm 5.99$ & $28.36 \pm 4.96$ & $22.11 \pm 3.27$ \\
\hline Total cholesterol (mmol/L) & $4.99 \pm 1.30$ & $4.79 \pm 0.83$ & $3.99 \pm 0.65$ \\
\hline HDL-chol (mmol/L) & $0.87 \pm 0.29$ & $1.16 \pm 0.20$ & $0.96 \pm 0.20$ \\
\hline LDL-chol (mmol/L) & $3.27 \pm 1.17$ & $3.01 \pm 1.07$ & $2.43 \pm 0.64$ \\
\hline Triglycerides $(\mathrm{mmol} / \mathrm{L})$ & $1.49 \pm 1.66$ & $1.50 \pm 1.39$ & $1.31 \pm 0.61$ \\
\hline Blood glucose & $6.00 \pm 0.52$ & $6.11 \pm 0.83$ & $\mathrm{~N} / \mathrm{A}$ \\
\hline Creatinine & $101.21 \pm 2.87$ & $99.58 \pm 3.69$ & $\mathrm{~N} / \mathrm{A}$ \\
\hline Hypertensive heart damage & $(\mathrm{n}=21)$ & - & \\
\hline Hypertensive brain damage & $(n=4)$ & $(n=2)$ & \\
\hline Hypertensive kidney damage & $(n=6)$ & $(n=4)$ & \\
\hline Hypertensive eye damage & $(n=2)$ & $(n=2)$ & \\
\hline Smoking & 21 & 16 & 8 \\
\hline Count & 32 & 24 & 22 \\
\hline
\end{tabular}

Data are presented as mean $\pm \mathrm{SD}$

Legend: BMI- body mass index; DBP- diastolic blood pressure; HDL- high density lipoprotein cholesterol; HFmrEF+LVHheart failure with mid-range ejection fraction and left ventricular hypertrophy; HFmrEF-LVH-heart failure with mid-range ejection fraction without left ventricular hypertrophy; LDL- low density lipoprotein cholesterol; SBP- systolic blood pressure 
rest in supine position. Blood pressure measuring was performed by „Riester“ blood pressure measuring tool - Type- Precisa ${ }^{\circledR} \mathrm{N} ; \varnothing 64$ mm aluminum, Single-tube, Cotton hook cuff, adult, No. 1362-104.

\section{Electrocardiography}

Electrocardiography (ECG) was performed for LVH assessment (Sokolow-Lyon index $>35 \mathrm{~mm}$, or $\mathrm{R}$ in $\mathrm{aVL} \geq 11 \mathrm{~mm}$; Cornell voltage duration product $>2440 \mathrm{~mm} . \mathrm{ms}$, or Cornell voltage $>28 \mathrm{~mm}$ in men or $>20 \mathrm{~mm}$ in women $)^{14}$. ECG was performed by 12 -lead ECG machine „Fukuda“- Type FX 8322.

\section{Echocardiography}

Echocardiography was performed with General Electric (Vivid S5) with 4-MHz transducer. All measurements were obtained according to the European Association of Cardiovascular Imaging (EACVI) and The American Society of Echocardiography (ASE) criteria for Cardiac Chamber Quantification

Table 2. Echocardiographic data.

\begin{tabular}{cc}
\hline & Patients \\
\hline LVEDD & 48.57 \\
\hline LVESD & 36.49 \\
\hline LVEDV & 111.31 \\
\hline LVESV & 58.22 \\
\hline IVS & 12.20 \\
\hline LVPWD & 12.22 \\
\hline EF\% & 47.5 \\
\hline LA & 35.5 \\
\hline Count & 56
\end{tabular}

Data are presented as mean value by Echocardiography ${ }^{15}$ : echocardiographic LVH [LV mass index: men $>50 \mathrm{~g} / \mathrm{m}^{2}$; women $>47 \mathrm{~g} / \mathrm{m}^{2}$. (height in $\mathrm{m}$ ); indexation for BSA may be used in normal weight patients; LV mass/BSA $\mathrm{g} / \mathrm{m}^{2}>115$ (men) and $>95$ (women)] (Table 2).

\section{Laboratory tests}

1. Serum uric acid, glucose were determined. Total cholesterol, triglycerides concentrations, HDL were measured by enzyme assay (Boehringer Mannheim, Mannheim, Germany). LDL was calculated via Friedewald's formula.

2. Serum creatinine levels were measured and moderate CKD with eGFR>30-59 mL/min/1.73 m² (BSA) or severe CKD with GFR $<30 \mathrm{~mL} / \mathrm{min} / 1.73 \mathrm{~m}^{2}$ were assessed. If any HMOD was found, then patient was further consulted by a referring specialist (cardiologist, nephrologist, neurologist, ophthalmologist).

\section{ELISA}

Enzyme-linked immunosorbent assay (ELISA) was used for measuring AII and MMP-12 levels.

MMP-12 levels were measured in serum samples using (NV-DDXK-E-MMP12-1) Human MMP-12 ELISA kit, 96-well plate- Novus Biologicals according to the manufacturer's instructions.

AII levels were measured in serum samples using ELISA kit by ALPCO Diagnostics (Salem, MA, USA, 74-ANGHU-E01) according to the manufacturer's instructions.

\section{Statistical analyses}

The research data were processed with the computer programs EXCEL (Microsoft Corporation, Redmond, WA) and STATGRAPHICS plus

Table 3. Serum levels of MMP-12 in patients with essential hypertension and HFmrEF and healthy controls.

\begin{tabular}{cccccc}
\hline & $\begin{array}{c}\text { MMP-12 }(\mathrm{ng} / \mathrm{mL}) \\
\mathrm{M} \div(\mathrm{Q} 1 \mathrm{toQ3})\end{array}$ & $\begin{array}{c}\text { Comparison } \\
\text { with }\end{array}$ & & $\begin{array}{c}\text { MMP-12 }(\mathrm{ng} / \mathrm{mL}) \\
\mathrm{M} \div(\mathrm{Q} 1 \text { toQ3) }\end{array}$ & Comparison with \\
\hline \multirow{2}{*}{ Patients } & $\begin{array}{c}0.0033 \\
(0.0022,0.0071)\end{array}$ & $\begin{array}{c}\text { Controls } \\
\mathrm{p}=0.006\end{array}$ & HFmrEF+LVH & $\begin{array}{c}0.0033 \\
(0.0019,0.0059)\end{array}$ & $\begin{array}{c}\text { HFmrEF-LVH } \\
(\mathrm{p}>0.05)\end{array}$ \\
\hline \multirow{2}{*}{ Controls } & $\begin{array}{c}0.0075 \\
(0.0068,0.016)\end{array}$ & $\begin{array}{c}\text { Patients } \\
\mathrm{p}=0.006\end{array}$ & HFmrEF-LVH & $\begin{array}{c}0.0034 \\
(0.002,0.0068)\end{array}$ & $\begin{array}{c}\mathrm{HFmrEF}+\mathrm{LVH} \\
(\mathrm{p}>0.05)\end{array}$ \\
\hline
\end{tabular}

Table 4. Serum levels of angiotensin II in patients with essential hypertension and HFmrEF and healthy controls according to the presence of LVH.

\begin{tabular}{|c|c|c|c|c|c|}
\hline & $\begin{array}{c}\text { Angiotensin II }(\mathrm{ng} / \mathrm{mL}) \\
\mathrm{M} \div(\mathrm{Q} 1 \text { to } \mathrm{Q} 3)\end{array}$ & $\begin{array}{l}\text { Comparison } \\
\text { with }\end{array}$ & & $\begin{array}{c}\text { Angiotensin II }(n g / m L) \\
M \div(Q 1 \text { to } Q 3)\end{array}$ & Comparison with \\
\hline Patients & $\begin{array}{c}8.952 \\
(1.680,13.923) \\
\end{array}$ & $\begin{array}{c}\text { Controls } \\
\mathrm{p}=0.03\end{array}$ & HFmrEF+LVH & $\begin{array}{c}8.533 \\
(1.477,13.009) \\
\end{array}$ & $\begin{array}{c}\text { HFmrEF-LVH } \\
\mathrm{p}=0.04\end{array}$ \\
\hline Controls & $\begin{array}{c}1.539 \\
(0.585,7.141)\end{array}$ & $\begin{array}{l}\text { Patients } \\
p=0.03\end{array}$ & HFmrEF-LVH & $\begin{array}{c}1.333 \\
(0.477,6.932)\end{array}$ & $\begin{array}{c}\mathrm{HFmrEF}+\mathrm{LVH} \\
\mathrm{p}=0.04\end{array}$ \\
\hline
\end{tabular}




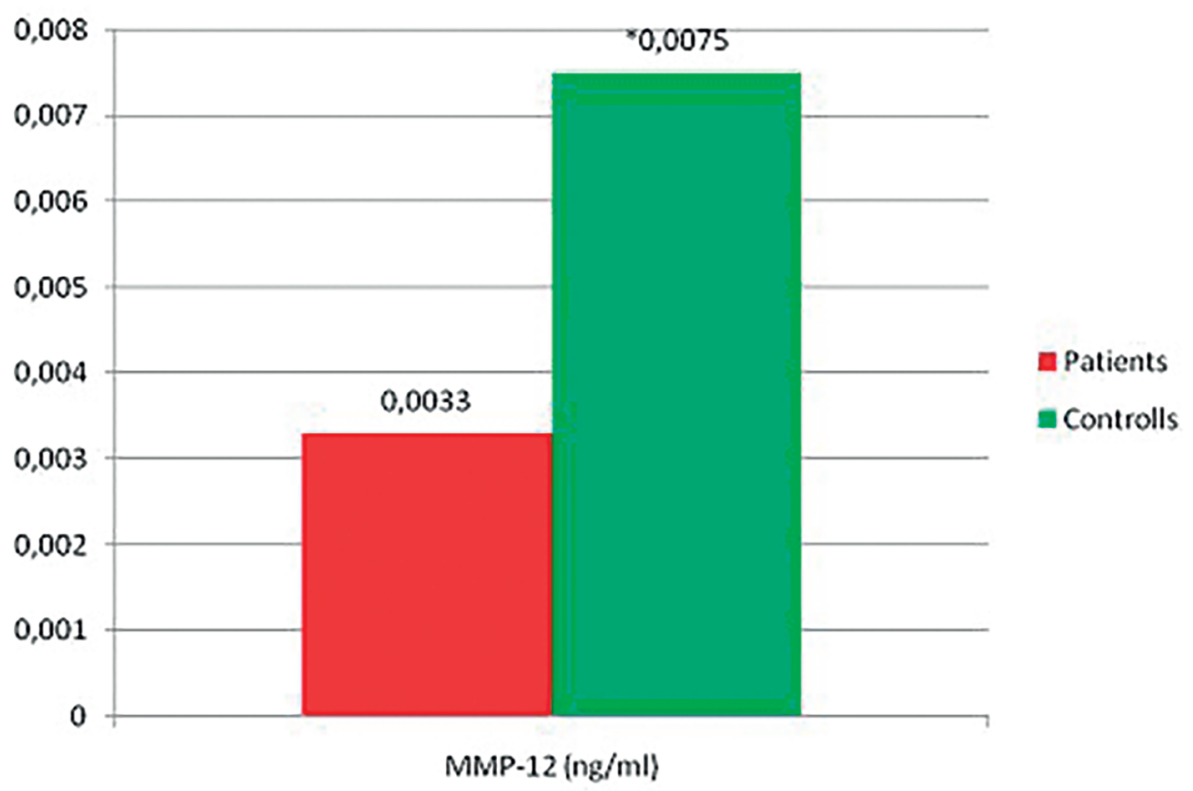

Figure 1. Serum levels of MMP-12 in patients with essential AH and HFmrEF and healthy controls. Serum MMP-12 levels were statistically significantly lower in patients, than in controls: $0.0033 \mathrm{ng} / \mathrm{mL}(0.0022 \div 0.0071)$ vs. $0.0075 \mathrm{ng} / \mathrm{mL}(0.0068 \div 0.016)(\mathrm{KW}=7.37 ; \mathrm{p}=0.006)$

\section{Angiotensin-II (pg/ml)}

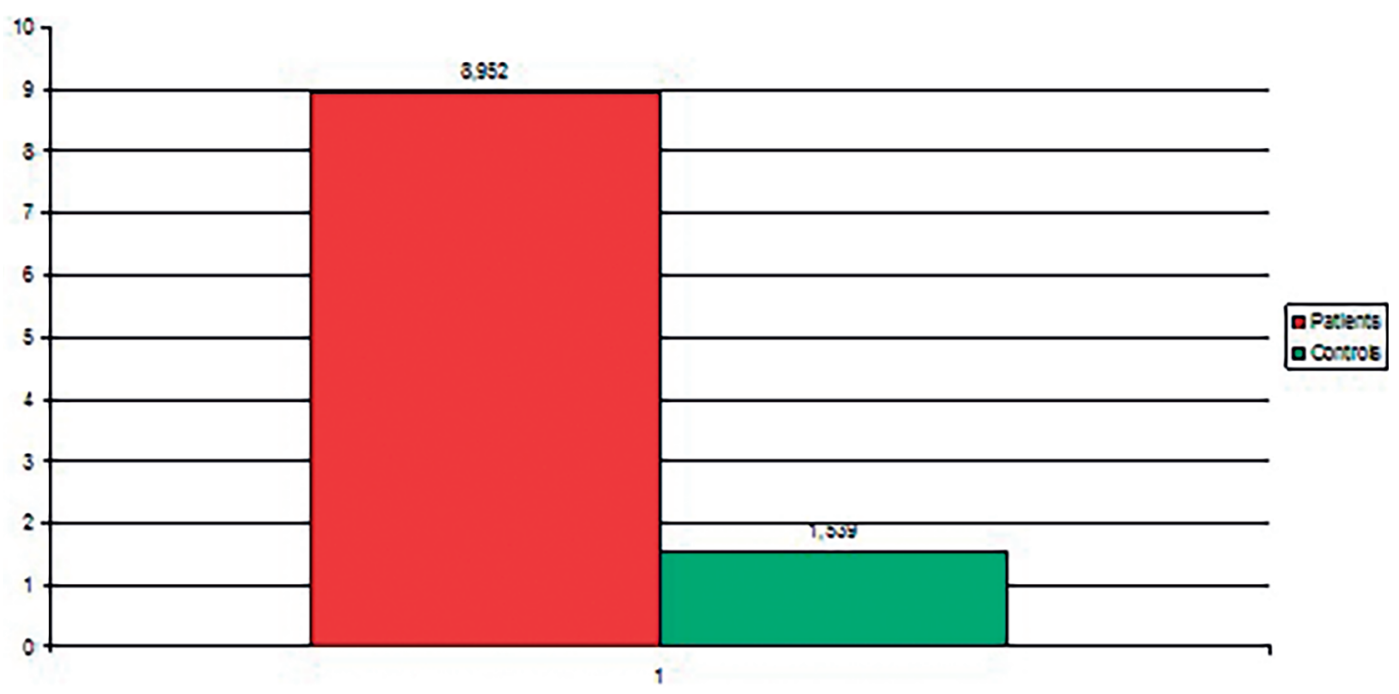

Figure 2. Serum levels of AII in patients with essential AH and HFmrEF and healthy controls. AII serum levels were significantly higher in patients compared to controls: $8.952 \mathrm{pg} / \mathrm{mL}(1.680 \div 13.923)$ vs. $1.539 \mathrm{pg} / \mathrm{mL}(0.585 \div 7.141)(\mathrm{p}=0.03)$.

(Manugistics, Rockville, MD) for WINDOWS. All results were described in tables, graphs, numerical values (mean $\pm \mathrm{SD}$, share indicators and correlations). The level of significance was determined as $p<0.05$. K-W (Kruskal-Wallis) test was performed in cases with different from normal distribution. Median (M) was used in K-W test, together with first and third quartile Q1 and Q3; (twenty-fifth and seventy-fifth percentile P25 and 75P). The Pearson's test was used for assessing of correlations. Multivariate regression analysis was performed too.

\section{Results}

Serum MMP-12 levels were statistically significant lower in patients, than in controls: $0.0033 \mathrm{ng} /$ $\mathrm{mL}(0.0022 \div 0.0071)$ vs. $0.0075 \mathrm{ng} / \mathrm{mL}(0.0068 \div 0.016)$ $(\mathrm{KW}=7.37 ; \mathrm{p}=0.006)$ (Table 3), (Fig. 1). There was not 


\section{Angiotensin II in HF mrEF+LVH vs. HF mrEF-LVH patients}

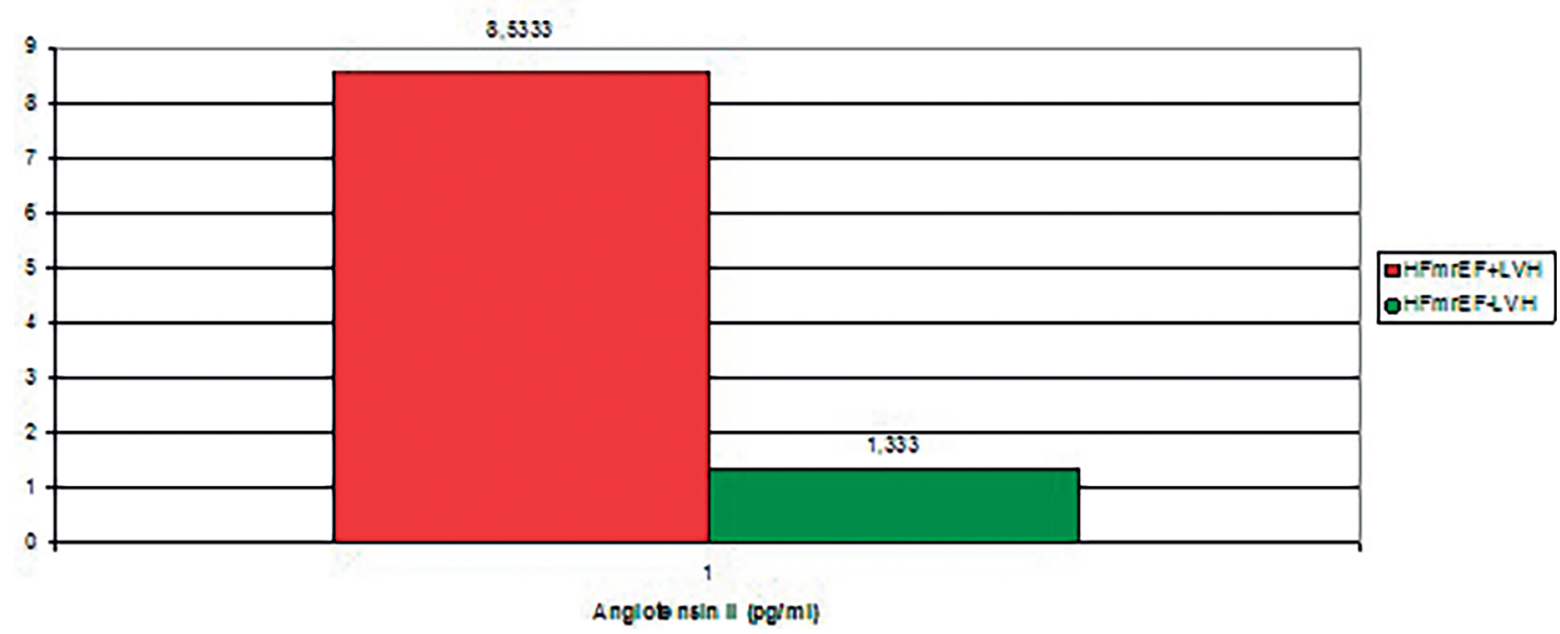

Figure 3. Serum levels of AII in patients with essential AH and HFmrEF and healthy controls according to presence of LVH. Patients with HFmrEF+LVH showed statistically significant higher levels of AII: $8.533 \mathrm{pg} / \mathrm{mL}(1.477 \div 13.009)$ than HFmrEF-LVH $1.333 \mathrm{pg} / \mathrm{mL}(0.477 \div 6.932)$ and healthy controls $1.539 \mathrm{pg} / \mathrm{mL}(0.274 \div 5.218) ;(\mathrm{KW}=3.48 ; \mathrm{p}=0.04)$.

MMP-12/All profiles

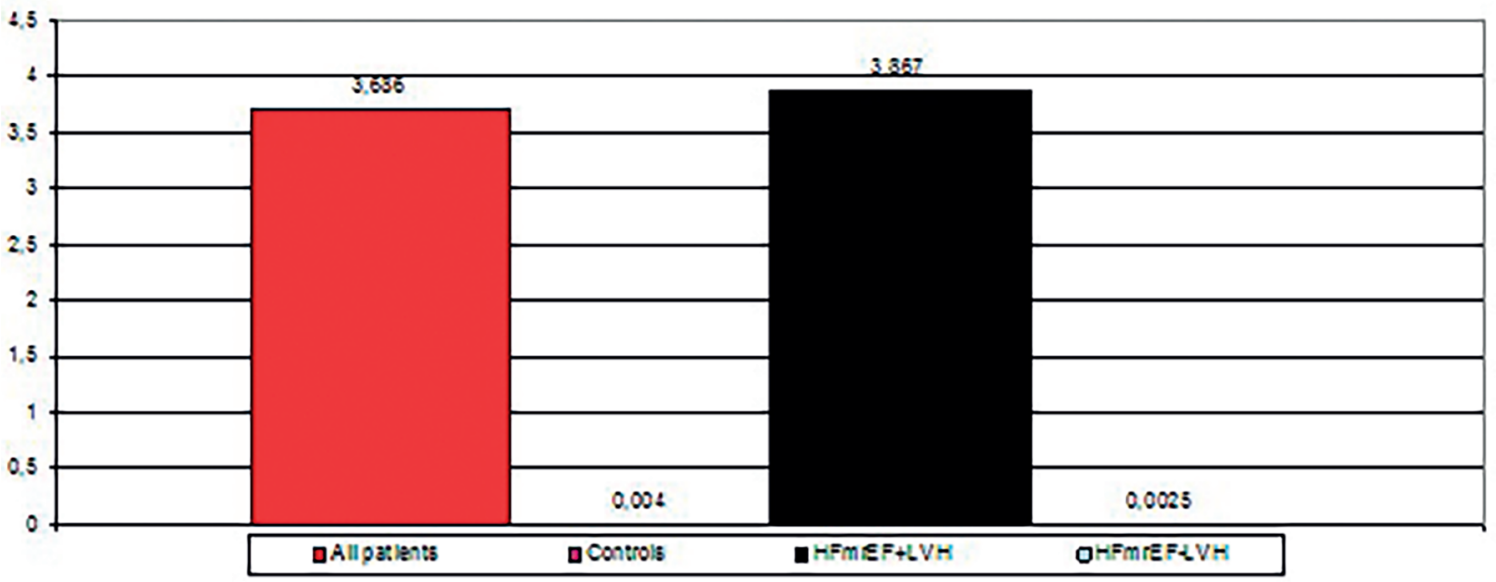

Figure 4. MMP-12/AII serum profiles of all subjects taking part in the current study. MMP-12/AII ratio was significantly higher in all patients than in controls 3.686 vs. $0.004(\mathrm{p}<0.001)$. MMP-12/AII ratio was significantly higher in patients with HFmrEF+LVH than in HFmrEF-LVH 3.867 vs. 0.0025 ( $\mathrm{p}<0.0001)$.

statistically significant difference between MMP-12 levels in patients with HFmrEF+LVH compared to HFmrEF-LVH ( $p>0.05)$. MMP-12 showed correlation with the grade of $\mathrm{AH}(\mathrm{r}=0.28 ; \mathrm{p}=0.03)$. AII serum levels were significantly higher in patients compared to controls: $8.952 \mathrm{pg} / \mathrm{mL}(1.680 \div 13.923)$ vs. $1.539 \mathrm{pg} / \mathrm{mL}(0.585 \div 7.141)(\mathrm{p}=0.03)$. Patients with HFmrEF+LVH showed statistically significant higher levels of AII: $8.533 \mathrm{pg} / \mathrm{mL}(1.477 \div 13.009)$ than HFmrEF-LVH $1.333 \mathrm{pg} / \mathrm{mL}(0.477 \div 6.932)$ and healthy controls $1.539 \mathrm{pg} / \mathrm{mL}(0.274 \div 5.218) ;(\mathrm{KW}=3.48$; $\mathrm{p}=0.04)$ (Table 4), (Fig. 2, 3). AII correlated with the stage of AH ( $r=0.47 ; p=0.001)$. The MMP-12/AII ratio was significantly higher in all patients than controls
3.686 vs. 0.004 ( $\mathrm{p}<0.001)$. MMP-12/AII ratio was significantly higher in patients with $\mathrm{HFmrEF}+\mathrm{LVH}$ than in HFmrEF-LVH 3.867 vs. 0.0025 (p<0.001) (Fig. 4).

\section{Disscussion}

The conceptual role of AII as a local mediator of fibrosis is suggested by several studies. Data show that circulating AII is chronically increased from either endogenous or exogenous sources ${ }^{16}$. Mounting evidence points towards an authentic signalling capacity for TIMPs distinct from their MMP-inhibitory activity. It also seems to play an important role in the regulation of apoptosis, cell survival, growth, migration, 
differentiation, angiogenesis, inflammation and overall ECM remodelling. Due to these mechanisms, TIMPs could play a vital role in the process of cardiac remodelling ${ }^{17,18}$. A suggestion about a link between TIMPs and the renin-angiotensin-system is reported $^{19}$. The authors identified human angiotensin-II-type-2-receptor as a novel TIMP-3 interacting partner, linking TIMP-3 with the renin-angiotensin system $^{19}$. Although the patho-physiological roles and signaling mechanisms of angiotensin-II-type-2-receptor are still largely unknown, they were shown to be increased during hypertrophy and ischemic heart disease.

Our results show decreased MMP-12 levels and increased AII in all patients. There was not a statistically significant difference between MMP-12 levels in patients with $\mathrm{HFmrEF}+\mathrm{LVH}$ compared to HFmrEF-LVH. Patients with HFmrEF+LVH showed statistically significantly higher levels of AII than HFmrEF-LVH and healthy controls. Interestingly, the MMP-12/AII profile is different according to presence of LVH. These results can summarize with three major findings:

MMP-12/AII ratio is significantly higher in all patients than in controls.

Patients with HFmrEF-LVH show decreased MMP-12/AII ratio.

The profile of patients with $\mathrm{HFmrEF}+\mathrm{LVH}$ shows increased MMP-12/AII ratio.

Data from the literature about the interaction between MMP-12 and AII and their complex turnover in patients with essential $\mathrm{AH}$ and HFmrEF are still insufficient. In 2017, a study showed that matrix metalloproteinase-12 is causally implicated in cardiovascular disease $^{20}$. Researchers evaluated and extended the reported association by examining the relationship between MMPs and vascular disease in both clinical and experimental samples. Plasma concentrations of MMP-1, MMP-3, MMP-7, MMP-10 and MMP-12 in $\mathrm{ng} / \mathrm{mL}$ were measured in 3394 subjects with high-risk for cardiovascular disease, using the Olink ProSeek CVD array. The plasma MMP-12 concentration showed an association with incident cardiovascular events (199 events over 36 months) and intima-media thickness progression over time $\left(\mathrm{p}=3.6 \times 10^{-5}\right)$. The single nucleotide polymorphisms (SNP) variant rs1892971 was strongly associated with plasma MMP-12 concentration $\left(\mathrm{p}=8 \times 10^{-29}\right)$ and weakly with susceptibility to coronary heart disease in the CardiogramplusC4D consortium study $\left(\mathrm{p}=8.8 \times 10^{-5}\right)$. The same SNP was also significantly associated with MMP-12 gene expression in peripheral blood mononuclear cells using microarrays from patients with carotid atherosclerosis $\left(n=96 ; p=1.8 \times 10^{-4}\right)$. The expression of MMP-12 was strongly increased in carotid plaques $(\mathrm{n}=127)$ compared with undiseased arteries $(n=10 ; p<0.001)$ and in plaques from symptomatic $(n=87)$ compared to asymptomatic patients $(n=40 ; p=0.03)$ and localised to CD68+ macrophages. Using proximity ligation assay, MMP-12 and elastin were demonstrated to co-interact in plaques in situ, particularly in regions with moderate to strong MMP-12 expression. In conclusion, this study suggests that MMP-12 is a causal factor in cardiovascular diseases, that is highly upregulated in human atherosclerotic plaques, where it interacts with elastin and appears to enhance macrophage invasion.

Arterial stiffening is a hallmark of aging and a risk factor for cardiovascular disease, yet its regulation is poorly understood ${ }^{21}$. Arterial stiffness plays a causal role in the development of systolic hyperten$\operatorname{sion}^{22,23}$. A study in 2015 showed that matrix metalloproteinase-12 is an essential mediator of acute and chronic arterial stiffening. The authors used mouse modeling to show that matrix metalloproteinase-12, a potent elastase, is essential for acute and chronic arterial stiffening ${ }^{24}$. MMP-12 was induced in arterial smooth muscle cells (SMCs) after acute vascular injury. In human aortic samples, MMP12 levels strongly correlate with markers of SMC stiffness. Authors concluded that MMP-12 causes arterial stiffening in mice and suggest that it functions similarly in humans.

In a study from 2018, the authors reported that elevated 20-hydroxyeicosatetraeonic acid (20-HETE) in metabolic syndrome regulates arterial stiffness and systolic hypertension via MMP-12 activation ${ }^{25}$. 20-HETE, a cytochrome P450 (CYP450)-derived arachidonic acid metabolite, is known to be elevated in resistance arteries in hypertensive animal models and loosely associated with obesity in humans. However, the role of 20-HETE in the regulation of large artery remodeling in metabolic syndrome has not been investigated. Soler A et al showed that elevated 20-HETE increases matrix metalloproteinase 12 activation in metabolic syndrome ${ }^{25}$. This process leads to increased degradation of elastin, increased large artery stiffness and increased systolic blood pressure. These findings may have implications in the management of systolic hypertension in patients with metabolic syndrome ${ }^{26}$.

Data from 2018 reported the relationship between matrix metalloproteinase-12, low-grade inflammation and kidney function in patients with resistant hypertension ${ }^{27}$. The authors found that matrix metalloproteinase-12 (MMP-12) modulates glomerular fibrogenesis and inflammation. MMP-12 plasma activity is elevated in resistant hypertension patients compared to patients with controlled hypertension. Moreover, MMP-12 plasma activity is 
associated with the deterioration of kidney function and hs-CRP. These findings suggest the important roles of MMP-12 in both hypertensive kidney injury and resistant hypertension development.

Our findings showed significantly higher MMP-12/AII ratio in all patients than in controls. Patients with HFmrEF-LVH showed decreased MMP-12/AII ratio. Patients with HFmrEF+LVH showed a profile presented by increased MMP-12/AII ratio. This study reveals altered elastin metabolism, focusing on pathological elastin degradation. We supposed that patients with essential $\mathrm{AH}$ and $\mathrm{HFmrEF}$ have reduced elastin degradation and blocked arterial stiffening. These alterations could accelerate higher grade and stage of hypertension and favor development and progression of left ventricular hypertrophy.

In our study, we report an association between changes in MMP-12/AII profile and left ventricular hypertrophy. Determination of serum MMP-12/ AII profile may be an useful method for monitoring the development and progression of LVH in patients with essential AH and HFmrEF. This is a pilot study. Although these findings should be confirmed in a larger study, our data suggest that alterations of MMP-12/ AII balance may play an important role in the structural, functional, and clinical manifestations of cardiac remodeling. However, further examination and prospective studies are needed to clarify the MMP-12 independent biological functions and fully understand its relevance and effects on left ventricular hypertrophy.

\section{Conclusions}

Our data suggest an association between changes in the levels of serum MMP-12, AII and grade and stage of $\mathrm{AH}$ in patients with HFmrEF. Determination of serum MMP-12/AII profile may be a useful method for monitoring the development and progression of LVH.

\section{Author Contributions:}

Conceptualization, A.N.; methodology, A.B. software, A.N., A.B.; validation, M.T.; formal analysis, A.N.; investigation, A.N., M.T.; resources, A.N.; data curation, A.N. and K.K.; writing-original draft preparation, A.N.; writing-review and editing, M.T.; visualization, K.K.; supervision, M.T.; project administration, A.N. All the authors have read and agreed with the final version of the article.

\section{Compliance with Ethics Requirements:}

"The authors declare no conflict of interest regarding this article"

"The authors declare that all the procedures and experiments of this study respect the ethical standards in the
Helsinki Declaration of 1975, as revised in 2008(5), as well as the national law"

\section{Acknowledgments: \\ None}

\section{Funding:}

This work was supported by the Centre of Scientific Research of Medical University, Pleven, Bulgaria.

\section{References}

1. Brown R, Ambler S, Mitchell M, Long C. The cardiac fibroblast: therapeutic target in myocardial remodeling and failure. Ann Rev Pharmacol Toxicol. 2005;45:657-2005.

2. Mann DL, Spinale FG. Activation of matrix metalloproteinases in the failing human heart breaking the tie that binds. Circulation. 1998;98:1699-1702.

3. Heusch G, Libby P, Gersh B, et al. Cardiovascular remodelling in coronary artery disease and heart failure. Lancet. 2014;383:1933-1943.

4. Draghici T, Negreanu L, Bratu OG, et al. Liver abnormalities in patients with heart failure. Arch Balk Med Union. 2018;53(1):76-81.

5. Mizuno T, Yau TM, Weisel RD, Kiani CG, Li RK. Elastin stabilizes an infarct and preserves ventricular function. Circulation. 2005;112:181-I88.

6. Shapiro SD, Kobayashi DK, Ley TJ. Cloning and characterization of a unique elastolytic metalloproteinase produced by human alveolar macrophages. J Biol Chem. 1993;268:23824-23829.

7. Matute-Bello G, Wurfel MM, Lee JS, et al. Essential role of MMP-12 in Fas-induced lung fibrosis. Am J Respir Cell Mol Biol. 2007;37: 210-221.

8. Goncalves I, Bengtsson E, Colhoun H, et al. Elevated plasma levels of MMP-12 are associated with atherosclerotic burden and symptomatic cardiovascular disease in subjects with type 2 diabetes. Arterioscler Thromb Vasc Biol. 2015;35:1723-1731

9. Iyer R, Patterson N, Zouein F, et al. Early matrix metalloproteinase-12 inhibition worsens post-myocardial infarction cardiac dysfunction by delaying inflammation resolution. Int J Card. 2015;185:198-208.

10. Mehta PK, Griendling KK. Angiotensin II cell signaling: physiological and pathological effects in the cardiovascular system. Am J Physiol Cell Physiol. 2007;292: 82-97.

11. Ponikowski P, Voors AA, Anker SD, et al. ESC Guidelines for the diagnosis and treatment of acute and chronic heart failure. European Heart Journal. 2016;37: 2129-2200.

12. Browatzki M, Larsen D, Pfeiffer C, et al. Angiotensin II stimulates matrix metalloproteinase secretion in human vascular smooth muscle cells via nuclear factor-kappaB and activator protein 1 in a redox-sensitive manner. Tissue J Vasc Res. 2005;42(5): 415-423.

13. Yaghooti H, Firoozrai M, Fallah S, Khorramizadeh MR. Angiotensin II differentially induces matrix metalloproteinase- 9 and tissue inhibitor of metalloproteinase- 1 production and disturbs MMP/TIMP balance. Avicenna J Med Biotechnol. 2010;2(2):79-85.

14. Lehtonen AO, Puukka P, Varis J, Porthan K, Tikkanen JT. Prevalence and prognosis of ECG abnormalities in 
normotensive and hypertensive individuals. J Hypertens. 2016;34:959-966.

15. Marwick TH, Gillebert TC, Aurigemma G, Chirinos J, Derumeaux G. Recommendations on the use of echocardiography in adult hypertension: a report from the European Association of Cardiovascular Imaging (EACVI) and the American Society of Echocardiography (ASE). Eur Heart J Cardiovasc Imaging. 2015;16: 577-605

16. Weber K. Extracellular matrix remodeling in heart failure. A role for de novo angiotensin II generation. Circulation. 1997;96(11): 4065-4082

17. Spinale FG. Myocardial matrix remodeling and the matrix metalloproteinases: influence on cardiac form and function. Physiol Rev. 2007;87(4): 1285-1342

18. Vanhoutte D, Schellings M, Pinto Y, Heymans S. Relevance of matrix metalloproteinases and their inhibitors after myocardial infarction: a temporal and spatial window. Cardiovasc Res. 2006;69(3): 604-613

19. Kang K, Park S, Rho S, Lee J. Tissue inhibitor of metalloproteinases-3 interacts with angiotensin II type 2 receptor and additively inhibits angiogenesis. Cardiovascular Research. 2008;79(1):150-160.

20. Hedin U, Mahdessian H, Perisic L, et al. IMPROVE study group. Matrix metalloproteinase 12 is causally implicated in cardiovascular disease. Arteriosclerosis, Thrombosis and Vascular Biology. 2016;36(1): A318

21. Gaman MA, Dobrica EC, Pascu EG, et al. Cardiometabolic risk factors for atrial fibrillation in type 2 diabetes mellitus: focus on hypertension, metabolic syndrome and obesity. Journal of Mind and Medical Sciences. 2019;6(1):157-161.

22. Diaconu C, Paraschiv B. Clinical characteristics of obese patients with hypertension and chronic ischemic heart disease. Romanian Journal of Internal Medicine. 2014;52(4):251-255.

23. Diaconu C. Comorbidities of hypertensive patients: are there differences between men and women? Arch Balk Med Union. 2016;51(3): 307-310.

24. Liu S, Bae Y, Yu C, et al. Matrix metalloproteinase-12 is an essential mediator of acute and chronic arterial stiffening. Sci Rep. 2015;5: 17189-17193

25. Soler A, Hunter I, Joseph G, et al. Elevated 20-HETE in metabolic syndrome regulates arterial stiffness and systolic hypertension via MMP12 activation. J Mol Cell Cardiol. 2018;117: 88-99

26. Diaconu C. Sindromul metabolic. Ed. Medicala, 2011.

27. Bezrodna L, Bezrodnyi V, Kuchmenko O, Kupchinska O, Serbeniuk K. Relationship between matrix metalloproteinase 12 , low-grade inflammation and kidney function in patients with resistant hypertension. Journal of Hypertension. 2018;36: e204-e208 